\title{
INTRARATER AND INTERRATER RELIABILITY OF MUSCLE TONE, ELASTICITY AND STIFFNESS CHARACTERISTICS MEASUREMENTS BY MYOTON-3 IN HEALTHY CHILDREN AGED 5-7 YEARS
}

\author{
Triinu Sakkool, Teet Meerits, Helena Gapeyeva \\ University of Tartu, Tartu, Estonia
}

\begin{abstract}
Background. Research literature highlights the need to use objective assessment tools to quantify muscle tone because all typically used clinical scales of muscle tone have reliability problems. Though hand-held device Myoton-3 has been used in research with children, its reliability has not been established. The aim of this study was to investigate intrarater and interrater reliability of muscle tone, elasticity and stiffness measurements by Myoton-3 in healthy children aged 5-7 years.

Methods. A total of 30 healthy children aged between 5 and 7 years participated in the study. Myoton- 3 device was used by two measurers to assess tibialis anterior (TA), rectus femoris (RF), biceps brachii (BB), medial head of gastrocnemius (GM), biceps femoris (BF), trapezius (TR) and triceps brachii (TB) muscle tone, elasticity and stiffness values. Measurements were conducted for intrarater reliability on two consecutive days and for interrater reliability on the same day.

Results. Intrarater reliability expressed as intra-class correlation of frequency, decrement and stiffness characteristics measurements was moderate to high, between $0.60-0.72$, while TR muscle ICC was low. Interrater reliability expressed as intra-class correlation of the frequency, decrement and stiffness characteristics measurements was high to very high, between $0.72-0.91$, while TR muscle ICC was low.

Conclusion. Moderate to high $(0.60-0.72)$ intrarater reliability and high to very high interrater reliability $(0.72-$ 0.91 ) was established for Myoton-3 measurements in healthy children aged 5-7 years. The Myoton-3 is a reliable device for measuring skeletal muscle tone, elasticity and stiffness in preschool children.
\end{abstract}

Keywords: Intra-class correlation, mechanical properties, children, Myoton-3.

\section{INTRODUCTION}

$\mathrm{M}$ uscle function could be characterized by muscle tone. Passive resting muscle tone (PRMT) is defined as state of muscle at rest when it has maintained a certain amount of tautness (Vain, Kums, Ereline, Pääsuke, \& Gapeyeva, 2015). PRMT is influenced by muscle passive length and its location in human body (Murayama, Watanabe, Kato, Uchiyama, \& Yoneda, 2012). While PRMT is expressed in stable position like lying, it has to be distinguished from postural muscle tone which plays an important role in maintaining the erect posture and equilibrium
(Vain et al., 2015). Muscle tone is related with mechanical properties of the skeletal muscles elasticity and stiffness (Viir, Laiho, Kramarenko, \& Mikkelson, 2006)

Research literature highlights the need to use objective assessment tools to quantify muscle tone (Aarrestad, Williams, Fehrer, Mikhailenok, \& Leonard, 2004; Lidström, Ahlsten, Hirchfield, \& Norrlin, 2009; Pomeroy et al., 2000). Studies about children with cerebral palsy have frequently used measures of spasticity, such as Ashworth and Tardieu scales (Alhusaini, Dean, Crosbie, Sheperd, 
\& Lewis, 2010; Bar-On et al., 2014; Yam \& Leung, 2006). Unfortunately, all typically used clinical scales of muscle tone have reliability problems (Aarrestad et al., 2004; Ansari et al., 2013; Pomeroy et al., 2000). Few instrumented methods in children have been used as well - devices like Myotonometer (Aarrestad et al., 2004; Lidström et al., 2009), Myoton-2 (Gavronski, Veraksitš, Vasar, \& Maaroos, 2007) and Myoton-3 (Gapeyeva \& Vain, 2007; Straubergaite, Bernecke, Muckus, \& Juodžbaliene, 2011; Straubergaite, Juodžbaliene, Tolocka, \& Muckus, 2012; Vahimets et al., 2006).

A hand-held myometer device Myoton-3 provides painless and objective assessment of mechanical properties of muscles (Gapeyeva \& Vain, 2008). Several studies have been conducted with children using device Myoton-3. For example, Gapeyeva and Vain (2007) investigated natural oscillation frequency of extensor digitorum, tibialis anterior and gastrocnemius muscles in 11-year-old boy with spastic hemiplegia. Vahimets et al. (2006) studied the influence of Trigenics Myoneural Treatment of six young basketball players' (aged $15.3 \pm 0.5$ years) muscle tone and elasticity of tibialis anterior, gastrocnemius, rectus femoris and biceps femoris muscles. Straubergaite et al. (2011) established the effect of horse-back riding on muscle tone, elasticity and stiffness of the lumbar erector spinae in healthy children aged 8-16 years. Straubergaite et al. (2012) also investigated the impact of physiotherapy on the lumbar erector spinae and gluteus medius muscle symmetry in children with and without cerebral palsy aged 8-16 years. Gapeyeva, Mitt, Ereline and Pääsuke (2015) studied the influence of 3-month physical therapy with the Atlant neuro-othopedic pneumosuit on muscle tone characteristics (frequency of muscle oscillation) of erector spinae, rectus abdominis, rectus and biceps femoris, gastrocnemius and tibialis anterior muscles in preschool children (aged 3-7 years) with spastic cerebral palsy.

Despite numerous investigations, there is no intra- or interrater reliability research of skeletal muscles by Myoton-3 in children. The aim of this study was to examine intra- and interrater reliability of muscle tone, elasticity and stiffness characteristics measurements using Myoton-3 in healthy children aged 5-7 years.

\section{METHODS}

Thirty children (15 girls and 15 boys) aged $5.6 \pm 0.6$ years (mean \pm SD) participated voluntarily in the study. Height, weight and BMI of participants are presented in Table 1. The subjects whose parents reported any physical impairment as well as other developmental disorders, orthopaedic problems, intellectual disability, sensory or speech disorder, did not take part in study. Children were from the same nursery school and had 1.5 hours of physical activity (PA) per week. Children's parents were asked about PA out of nursery school. Results showed that $10 \%$ of children had additional PA (gymnastics and football, 2-4 hours per week). One day before the study the children were asked to avoid physical training. For participation in the study, a written informed consent of children's parents and each child's assent were obtained. The study received the approval of the Ethics Committee of the University of Tartu for human studies.

Table 1. Anthropometric data of children $(n=30)$, mean \pm SD

\begin{tabular}{|c|c|c|c|}
\hline Characteristics & Mean & \pm SD & Range (Min-Max) \\
\hline Height (m) & 1.19 & \pm 0.07 & $1.07-1.32$ \\
\hline Body mass (kg) & 22.5 & \pm 4.4 & $16.4-31.5$ \\
\hline BMI (kg/m $\mathbf{m}^{\mathbf{2}}$ & 15.7 & \pm 1.7 & $12.2-20.3$ \\
\hline
\end{tabular}

Note. BMI - body mass index.

Measurements of anthropometric parameters. Height and body mass were measured on the first day of the two consecutive days. The body standing height was measured to the nearest $0.1 \mathrm{~cm}$ using a Martin portable anthropometer. Body mass was measured by digital scale, accurate to $50 \mathrm{~g}$ (Soehnle, Germany).

Measuring mechanical characteristics (tone, elasticity, stiffness). A hand held non-invasive device Myoton-3 and Myoton software (Müomeetria Ltd, Estonia) were used. The Myoton-3 device induces oscillation of the muscle tissue by a mechanical impact with a force up to $0.4 \mathrm{~N}$; it follows by quick release on the muscle belly. Muscle oscillations are registered by the accelerometer of the device with a sampling rate of $3200 \mathrm{~Hz}$, and a graph is formed based on this recording. The mass of the device's testing probe is $18 \mathrm{~g}$, diameter $3 \mathrm{~mm}$, and the kick time $15 \mathrm{~ms}$ (Vain et al., 2015). A Multi Scan pattern of 5 consecutive measurements at one point was measured and the mean of 5 measures was calculated using Myoton software (Vain, 2002). Frequency of muscle oscillations (FMO) $[\mathrm{Hz}]$ as an indicator of the tone, logarithmic decrement of the dampening of muscle oscillations (LDDMO) as an 
indicator of the elasticity and stiffness of the muscle (ST) $\left[\mathrm{Nm}^{-1}\right]$ were measured in relaxed (passive muscle tone) condition (Vain et al., 2015).

Seven muscles were tested bilaterally and muscles were always measured in same order tibialis anterior (TA), rectus femoris (RF), biceps brachii (BB), medial head of gastrocnemius (GM), biceps femoris (BF), trapezius (TR) and triceps brachii (TB) muscles. Right body side muscles were constantly measured before. Marks were made in the middle of the muscle belly, which was identified with palpation and muscle contraction. Measuring point was marked using a non-toxic permanent Surgical Skin Marker (Viscot Medical LLC, USA). Participants were asked to lie in comfortable position on the massage table and to relax before measuring. To measure TA, RF and BB muscles, subjects were supported with special pillows under the head and knees (Figure 1A), for measuring GM, BF, TR and TB muscles, pillows were placed under ankle, and the head was in the aperture of massage table to provide relaxation of the muscles (Figure 1B).

Study design. Measurements were performed on two consecutive days of a week at the same time, in the same room and temperature (recorded using digital thermometer, it was maintained at $21^{\circ} \mathrm{C}$ ). Measurements were carried out by two different qualified measurers (M1 and M2). Firstly, measurements were done for intrarater

Figure 1A. Subject in a supported supine position for measuring TA, RF and BB muscles

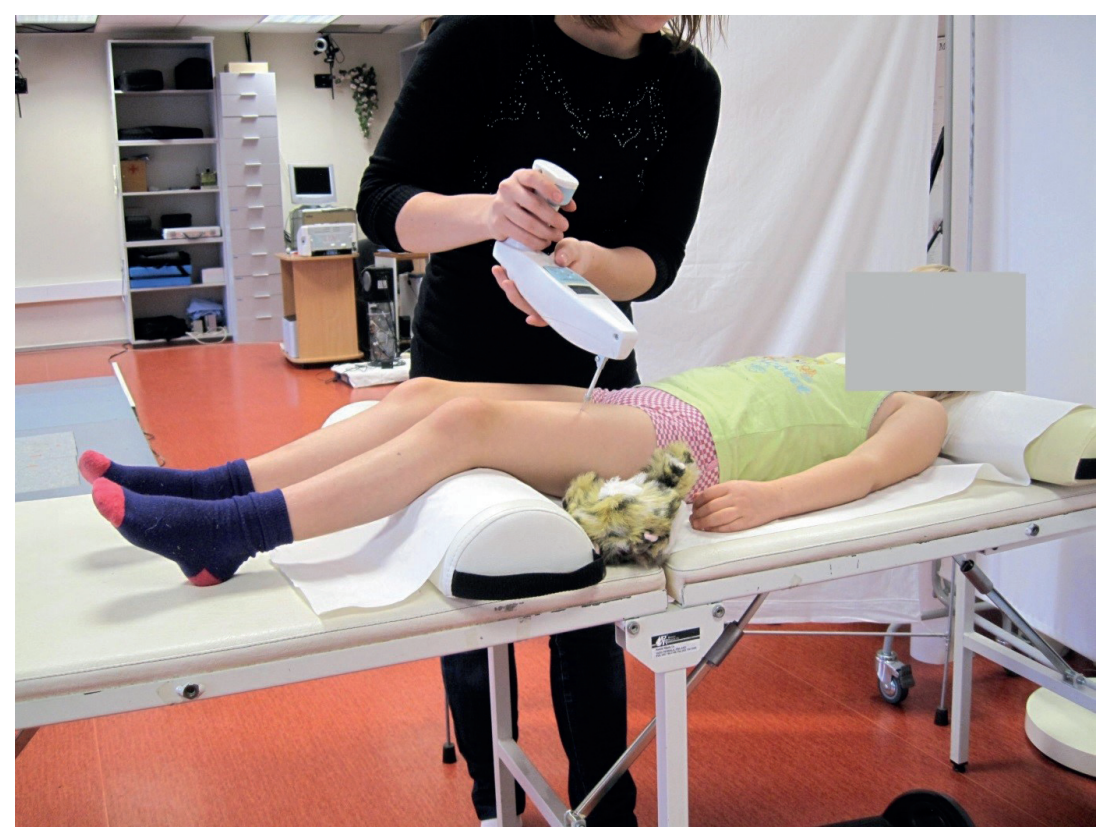

Figure 1B. Subject in a supported prone position for measuring GM, BF, TR and TB muscles

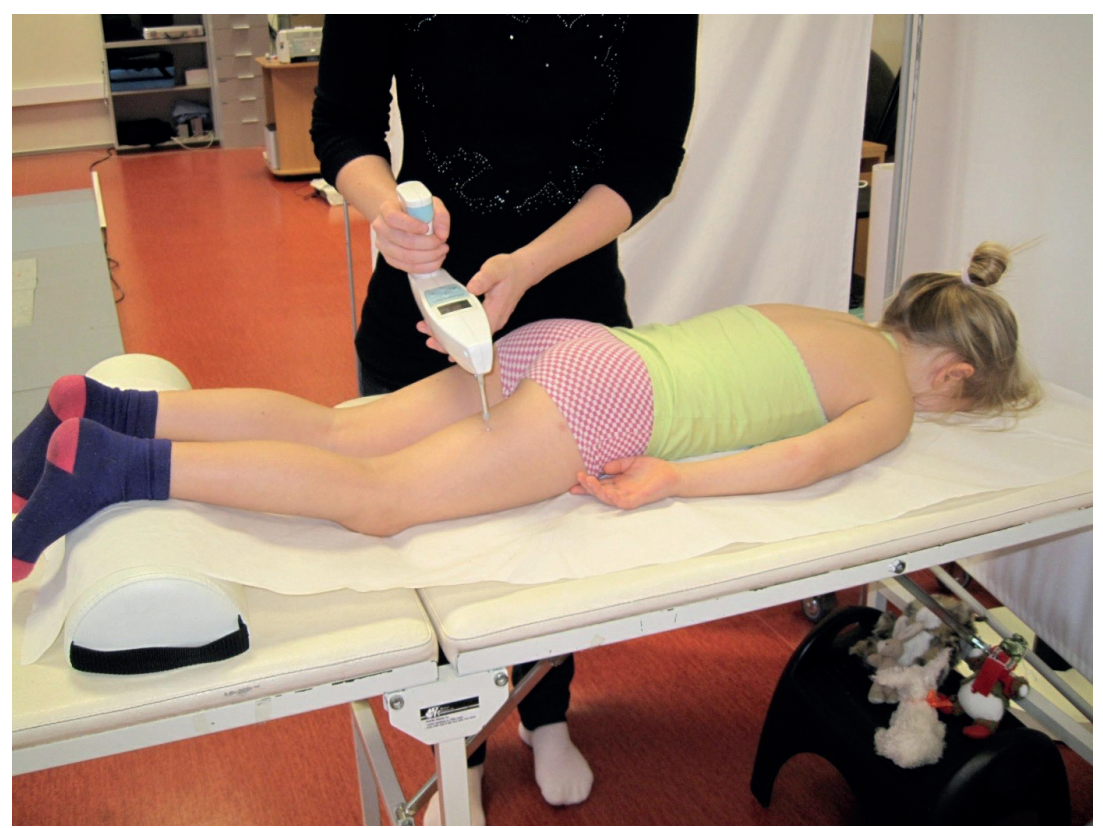


reliability - each muscle was measured by M1 on two consecutive days. The interval between two measurements by M1 was 24 hours. Secondly, measurements were performed for interrater reliability - on the second day one set of the same muscles were measured by M2 as before by M1 to compare the results of two sets. The interval between the two sets of measurements (M1 and M2) was 15 to 30 minutes. During the pause children were asked to lie supine on massage table while reading a book or watching videos from smartphone.

Statistical analysis. Data was analysed using Microsoft Excel 2013 and it is presented as mean value \pm standard deviation (SD). Mean values from day one and day two also from set one set two were compared using Student's $t$-test. The lowest level of statistical significance was set at $p<.05$. Pooled data of the left and the right body side was used.
Reliability between trials at between days and at the same day (within session) as an intra-class correlation coefficient (ICC) model 3, 2 (two-way mixed model) was used (Shrout \& Fleiss, 1979). For interpreting ICC, the following scale was used: very high $=1.00-.90 ;$ high $=.89-.70 ;$ moderate $=$ $.69-.50$; low $=.49-.26$ (Domholdt, 1993). Standard error of measurement (SEM) was calculated using formula $\mathrm{SEM}=\mathrm{SD} * \sqrt{ }(1-\mathrm{ICC}$ (Fleiss, 2007). Minimal detectable difference (MDD) was calculated using formula $\mathrm{MCC}=\mathrm{SEM}^{*}(\sqrt{ } 2) * 1.96$ (Fletcher \& Bandy, 2008).

\section{RESULTS}

The muscle frequency, elasticity and stiffness characteristics during measurements by $\mathrm{M} 1$ and intrarater reliability ICC results are presented in Table 2. Values of FMO were highest in TA

\begin{tabular}{|c|c|c|c|c|c|}
\hline $\begin{array}{c}\text { Characteristics/ } \\
\text { muscle }\end{array}$ & DAY 1 (M1) & DAY 2 (M1) & ICC & SEM & MDD \\
\hline \multicolumn{6}{|l|}{$\begin{array}{l}\text { Frequency of muscle } \\
\text { oscillations }(\mathrm{Hz})\end{array}$} \\
\hline TA & $14.3 \pm 1.6$ & $14.1 \pm 1.3$ & .66 & 0.85 & 2.34 \\
\hline RF & $12.6 \pm 0.9$ & $12.5 \pm 0.9$ & .65 & 0.54 & 1.49 \\
\hline BB & $12.3 \pm 0.8$ & $12.2 \pm 0.7$ & .66 & 0.42 & 1.17 \\
\hline GM & $12.3 \pm 0.8$ & $12.2 \pm 0.8$ & .60 & 0.49 & 1.36 \\
\hline BF & $12.8 \pm 1.1$ & $12.7 \pm 1.0$ & .72 & 0.56 & 1.55 \\
\hline TR & $10.8 \pm 0.9$ & $10.8 \pm 0.9$ & .10 & 0.84 & 2.33 \\
\hline TB & $10.9 \pm 0.9$ & $10.9 \pm 0.9$ & .66 & 0.51 & 1.41 \\
\hline \multicolumn{6}{|l|}{$\begin{array}{l}\text { Logarithmic decrement } \\
\text { of dampening of muscle } \\
\text { oscillations }\end{array}$} \\
\hline TA & $0.9 \pm 0.1$ & $0.9 \pm 0.1$ & .60 & 0.09 & 0.25 \\
\hline RF & $1.2 \pm 0.2$ & $1.2 \pm 0.2$ & .62 & 0.12 & 0.33 \\
\hline BB & $1.0 \pm 0.1$ & $1.0 \pm 0.1$ & .62 & 0.09 & 0.24 \\
\hline GM & $1.0 \pm 0.1$ & $1.0 \pm 0.2$ & .64 & 0.09 & 0.26 \\
\hline BF & $1.2 \pm 0.2$ & $1.2 \pm 0.2$ & .65 & 0.10 & 0.27 \\
\hline TR & $1.0 \pm 0.1$ & $1.0 \pm 0.2$ & .09 & 0.20 & 0.54 \\
\hline TB & $1.1 \pm 0.2$ & $1.1 \pm 0.2$ & .61 & 0.14 & 0.38 \\
\hline \multicolumn{6}{|l|}{ Stiffness (N/m) } \\
\hline TA & $268.0 \pm 26.3$ & $268.1 \pm 29.8$ & .66 & 16.32 & 45.24 \\
\hline RF & $182.8 \pm 18.4$ & $180.6 \pm 17.5$ & .62 & 11.03 & 30.56 \\
\hline BB & $190.1 \pm 20.6$ & $188.9 \pm 19.8$ & .60 & 12.71 & 35.23 \\
\hline GM & $172.5 \pm 14.3$ & $174.4 \pm 15.4$ & .61 & 9.28 & 25.71 \\
\hline BF & $183.8 \pm 19.3$ & $184.0 \pm 19.1$ & .61 & 11.89 & 32.94 \\
\hline TR & $173.8 \pm 32.2$ & $177.9 \pm 29.5$ & .06 & 29.88 & 82.82 \\
\hline TB & $154.6 \pm 24.6$ & $159.3 \pm 24.2$ & .61 & 15.26 & 42.26 \\
\hline
\end{tabular}

Table 2. Values of muscle frequency, elasticity, stiffness (mean \pm SD) and intrarater intra-class correlation (ICC), standard error of measurement (SEM), and minimal detected change in values of between days data (MDD) in healthy children aged 5-7 years $(n=30)$.

Note. M1- measurer 1; $\mathrm{TA}$ - tibialis anterior, RF rectus femoris, $\mathrm{BB}$ - biceps brachii, GM -medial head of gastrocnemius, $\mathrm{BF}-$ biceps femoris, TR - trapezius, TB - triceps brachii muscle. Data for the right and left sides are pooled. 
muscle, lowest in TR muscle. The TA muscle values differed from its antagonistic muscle GM values about $14 \%(p<.01)$, which was bigger than the difference between measured muscles BB and TB in the upper limb, where it was $11 \%$ $(p<.01)$. The values of lower limb muscles RF and $\mathrm{BF}$ did not differ significantly. The values of the LDDMO had a similar tendency as FMO - TA and GM muscle values differed more than BB and TB muscles, while RF and BF muscles had similar values. In ST the highest values were in TA muscle. If we compare TA muscle with GM muscle, there is a contrast $-37 \%(p<.01)$. The lowest ST values were in $\mathrm{TB}$, comparing with $\mathrm{BB}$, the difference was $17 \%(p<.01)$. Like before, $\mathrm{RF}$ and $\mathrm{BF}$ muscles did not differ significantly.

Between the days, reliability of TA, RF, $\mathrm{BB}, \mathrm{GM}$ and $\mathrm{TB}$ frequency measurements was moderate (ICC between .69 and .50). ICC of BF frequency measurements was high -.72 . Results of TR frequency measurements showed no reliability (ICC .1). ICC results of all measured muscles elasticity (.60 to .65$)$ and stiffness (.60 to .66) were all medium except of TR, where ICC values were .09 and .06 , respectively.

The muscle frequency, elasticity and stiffness measurements interrater reliability ICC values are presented in Table 3. Within session of measurements Set1 (M1) and Set2 (M2), values of the FMO were highest in TA muscle $(14 \%$ $(p<.01)$ different from GM muscle), lowest in TR and TB muscles. Antagonistic muscles BB and TB had 11\% $(p<.01)$ difference between values. Contrary to other muscles, BF and RF muscles had very similar values. The same trends as before in the difference of antagonistic muscles also appeared in the values of LDDMO. As between days' measurements, within session values of
Table 3. Results of muscles frequency, elasticity, stiffness (mean \pm SD) and interrater intra-class correlation (ICC), standard error of measurement (SEM) and minimal detected change values of within session data (MDD) in healthy children aged 5-7 years $(n=30)$.

Note: M1 - measurer 1, M2 - measurer 2; TA tibialis anterior, $\mathrm{RF}$ - rectus femoris, BB - biceps brachii, GM- medial head of gastrocnemius, BF - biceps femoris, TR - trapezius, TB - triceps brachii muscle. Data for the right and left sides are pooled.

\begin{tabular}{|c|c|c|c|c|c|}
\hline $\begin{array}{c}\text { Characteristics/ } \\
\text { muscle }\end{array}$ & Set 1 (M1) & Set 2 (M2) & ICC & SEM & MDD \\
\hline \multicolumn{6}{|l|}{$\begin{array}{l}\text { Frequency of muscle } \\
\text { oscillations }(\mathrm{Hz})\end{array}$} \\
\hline TA & $14.1 \pm 1.3$ & $14.4 \pm 1.3$ & .72 & 0.69 & 1.91 \\
\hline RF & $12.5 \pm 0.9$ & $12.3 \pm 0.9$ & .78 & 0.43 & 1.20 \\
\hline BB & $12.2 \pm 0.7$ & $12.3 \pm 0.7$ & .76 & 0.33 & 0.92 \\
\hline GM & $12.2 \pm 0.8$ & $12.2 \pm 0.7$ & .78 & 0.35 & 0.96 \\
\hline BF & $12.7 \pm 1.0$ & $12.6 \pm 0.9$ & .91 & 0.29 & 0.81 \\
\hline TR & $10.8 \pm 0.9$ & $11.0 \pm 0.7$ & .02 & 0.78 & 2.15 \\
\hline TB & $10.9 \pm 0.9$ & $10.9 \pm 0.9$ & .79 & 0.40 & 1.11 \\
\hline \multicolumn{6}{|l|}{$\begin{array}{l}\text { Logarithmic decrement } \\
\text { of dampening of muscle } \\
\text { oscillations }\end{array}$} \\
\hline TA & $0.9 \pm 0.1$ & $0.9 \pm 0.2$ & .73 & 0.08 & 0.23 \\
\hline RF & $1.2 \pm 0.2$ & $1.2 \pm 0.2$ & .74 & 0.09 & 0.26 \\
\hline BB & $1.0 \pm 0.1$ & $1.0 \pm 0.1$ & .76 & 0.07 & 0.19 \\
\hline GM & $1.0 \pm 0.2$ & $1.0 \pm 0.1$ & .78 & 0.08 & 0.96 \\
\hline BF & $1.2 \pm 0.2$ & $1.2 \pm 0.2$ & .75 & 0.09 & 0.78 \\
\hline TR & $1.0 \pm 0.2$ & $1.0 \pm 0.1$ & .17 & 0.17 & 0.47 \\
\hline TB & $1.1 \pm 0.2$ & $1.1 \pm 0.2$ & .78 & 0.09 & 0.26 \\
\hline \multicolumn{6}{|l|}{ Stiffness (N/m) } \\
\hline TA & $268.1 \pm 29.8$ & $268.8 \pm 30.4$ & .75 & 15.01 & 41.49 \\
\hline RF & $180.6 \pm 17.5$ & $179.8 \pm 17.6$ & .85 & 6.76 & 18.74 \\
\hline BB & $188.9 \pm 19.8$ & $190.8 \pm 19.6$ & .80 & 8.78 & 24.32 \\
\hline GM & $174.4 \pm 15.4$ & $174.6 \pm 14.8$ & .77 & 7.21 & 18.97 \\
\hline BF & $184.0 \pm 19.1$ & $185.2 \pm 19.3$ & .85 & 6.32 & 17.53 \\
\hline TR & $177.9 \pm 29.5$ & $180.5 \pm 22.2$ & .49 & 18.58 & 51.50 \\
\hline TB & $159.3 \pm 24.2$ & $161.6 \pm 23.4$ & .79 & 10.87 & 30.11 \\
\hline
\end{tabular}


ST were highest in TA muscle, although there is a contrast with GM muscle $-37 \%(p<.01)$. The lowest values were in $\mathrm{TB}$, compared with $\mathrm{BB}$, the difference was $15 \%(p<.01)$. RF and BF muscle values did not differ significantly.

Interrater ICC of BF muscle frequency measurements was very high (.91) and TA, RF, BB, GM, TB muscles measurements showed high ICC values (.72-.79). Only TR showed very low ICC values of frequency measurements (.02). All measured muscle characteristics, except for TR, showed high reliability of elasticity measurements within session, ICC values were in the range of .73 to .78 . The ICC of stiffness measurements was high -.75 to .85 for all measured muscles, except TA, which was low (.49).

ICC values of measurements within session (interater reliability) were higher than those between days. SEM values were higher in between days' (intrarater reliability) measures than the ones within session and MDD were also higher in between days (Table 2 and Table 3). There were no significant differences between means of measured characteristics between days and within session values (Set 1 and Set 2).

\section{DISCUSSION}

The present study is the first to estimate intra- and interrater reliability of Myoton-3 measurements of muscle tone, elasticity and stiffness characteristics in healthy children aged 5-7 years. Our study included investigation of seven skeletal muscles from different body regions. The main findings of our study were: intrarater reliability expressed as intra-class correlation of the frequency, decrement and stiffness were moderate to high for all measured muscles, between .60-.72, except TR muscle. Interrater reliability expressed as intra-class correlation of the frequency, decrement and stiffness were high to very high for all measured muscles, between .72-.91, except TR muscle.

Previously, Marusiak, Kisiel-Sajewicz, Jaskolska and Jaskolski (2010) found excellent repeatability of the muscle stiffness measurements in ten elderly women (aged $77 \pm 4$ years) and in eight Parkinson disease diagnosed (PD) women (aged $77 \pm 3$ years). In their study, the Myoton-3 device was used for measuring muscle stiffness of short head of BB muscle in supine relaxed position. Intra-class correlation was .93 in healthy subjects and .99 in the PD group. In our study, ICC values in this characteristic were lower, but our group of subjects was significantly different form previously described research. Bizzini and Mannion (2003) also investigated test-retest reliability of muscle stiffness measurements. The Myoton-2 myotonometer was used in their study for measuring BF, vastus lateralis, RF, lateral head of gastrocnemius and GM muscles at rest in ten volunteers (five males, five females, their mean age was 40). In this research they measured muscles on two consecutive days. The ICC values of BF were .80-.91, RF .84-.85, GM .80-.88. In our study, ICC values of stiffness in these muscles were slightly lower. It can be explained by differences of devices and subjects. While Myoton-2 has similar working principles as Myoton-3, it has larger mass of the testing end (37 g) than Myoton-3 (18 g). Additionally, Bizzini and Mannion (2003) made 20 consecutive measurements at each site while we made 5 consecutive measurements. The mean age of subjects in the later study was $40 \pm 13$ years, but in our study children aged 5-7 years were measured.

Lidström et al. (2009) investigated reliability of Myotonometer (Myo-Tech, Missoula, Mont) measurements by assessing muscle tone in RF muscle in children with cerebral palsy $(\mathrm{n}=15$, aged $7-15$ years) and children without disabilities ( $n=15$, aged $6-15$ years). They also measured differences in muscle tone between groups and contracted or relaxed conditions. They found high to very high (.7-1.0) intrarater intra-class correlation under both conditions and in both groups. Interrater intra-class correlation was high to very high (.7-1.0) under both conditions in the control group and in the cerebral palsy group under contracted conditions. Our study showed high (.74-.85) interrater intra-class correlation in relaxed RF muscle characteristics. Differently, our intrarater intra-class correlation was moderate (.62-.65). Firstly, it was probably affected by the time between two measurements, which was at least 24 hours. The possible explanation why they received greater reliability between values of intrarater measurements is that their study was committed on the same day. In our research we can see the tendency as well - interrater ICC values were higher than intrarater ICC values because measurements for the first one were made on the same day and for the other on two consecutive days. 
Secondly, there were two different devices used in these studies for measuring. Myotonometer (MyoTech, Missoula, Mont) which Lidström et al. (2009) used is an electronic device where the probe is pressed perpendicularly against a muscle, the outer cylinder remains stationary as the inner cylinder pushes onto and compresses the underlying tissue. Eight tissue displacement values are registered for each pressure, corresponding to eight levels of force $(0.25,0.50,0.75,1.0,1.25,1.50,1.75,2.00 \mathrm{~kg})$. In our study we used Myoton-3 which induces oscillation of the muscle tissue by a short (kick time $15 \mathrm{~ms}$ ) mechanical impact with a very low force (up to $0.4 \mathrm{~N}$ ). The testing probe diameter of Myoton-3 device is $3 \mathrm{~mm}$ while Myotonometer's (Myo-Tech, Missoula, Mont) probe has a diameter of $1 \mathrm{~cm}$ (Oliva-Pascual-Vaca et al., 2014).

Studying intrarater reliability on two consecutive days we have to considerate that healthy children aged 5-7 years are physically active. To analyse the effect of physical activity (PA) on measurement results, children's parents were asked about PA out of nursery school. Results showed that $10 \%$ of children had additional PA (gymnastics and football, 2-4 hours per week). We asked children to avoid additional PA on the day before measuring. Probably, children did not exercise as they use to do, but it is questionable how much they ran or jumped before the measuring day or on the same day. So it is difficult to analyse what effect physical activity had on our intrarater reliability results. Perhaps we should have done all measurements - intra- and interrater reliability on the same day like Lidström et al. (2009).

In our study good intra- and interreliability ICC was noted for all measured muscles, except for TR muscle. Viir et al., (2006) examined trapezius muscle tone with Myoton-2 myometer in 20 women (5 healthy, 15 with various musculoskeletal disorders), their mean age was 44.2 years. Interrater reliability was investigated by two measurers within the same session. ICC values were very high (.97-.99). The subjects were in a relaxed sitting position, while in our study children were in a relaxed prone position. This could be one of the causes of differences in ICC results between two studies. Other possible explanation is that the position of the child's head in our study was with its support on the aperture edge of the massage table (length $15 \mathrm{~cm}$, width $9.5 \mathrm{~cm}$ ) which is made for adult head size. Indeed, a 5-7-year-old child has smaller head circumference than adult: in the study of Bartholomeusz, Courchesne and Karns (2002) it has been noted that the head circumference of children aged 6 years and younger was from $48.6 \mathrm{~cm}$ to $56.1 \mathrm{~cm}$, in adults - from $55.2 \mathrm{~cm}$ to $62.3 \mathrm{~cm}$. For this reason children have to hold neck against gravity while the main force is carried on the frontal part of the head because the head aperture is too big for children. Despite the request for relaxation of muscles and palpation before measurement, the head position in case of such aperture of massage table apparently caused stress (contraction) to the neck and shoulder girdle muscle groups, including TR muscle.

The strength of the present study is the investigation of intrarater and interrater reliability of Myton-3 measurements of skeletal muscle tone, elasticity and stiffness in healthy preschool children, which has not been investigated before. Only healthy children in preschool age were included in the study. Our measurers had earlier practical experience with Myoton-3 device and did have quite a big number of subjects. Also we tried to avoid the effect of different diseases and physical activity on measured characteristics. The study also had some limitations. We studied intrarater reliability between two consecutive days, but we do not know how children's physical activity affected the results. Therefore it is definitely necessary to compare measurement results which are conducted only on the same day. In the future, it is recommended to choose more appropriate position for the child's body segments for measuring neck and trunk muscles.

\section{CONCLUSIONS}

Results suggest that measurements of skeletal muscle tone, elasticity and stiffness characteristics by Myoton-3 have moderate intrarater and high interrater intra-class correlation values in healthy $5-7$-year-old children. The Myoton-3 is a reliable device for the estimation of muscle tone and mechanical properties in children. It can be recommended to choose an appropriate position to ensure the achievement of muscle maximal voluntary relaxation during measurement, especially in preschool children in the aspects of their musculoskeletal system development peculiarities. 
Acknowledgement. This research has been partially supported by the Ministry of Education and Research of the Republic of Estonia, Project
No. IUT20-58 "Physical performance and health: adaptational and age-related aspects".

\section{REFERENCES}

Aarrestad, D. D., Williams, M. D., Fehrer, S. C., Mikhailenok, E., \& Leonard, C. T. (2004). Intra- and interrater reliabilities of the myotonometer when assessing the spastic condition of children with cerebral palsy. Journal of Child Neurology, 19(11), 894-901.

Alhusaini, A. A. A., Dean, C. M., Crosbie, J., Sheperd, R. B., \& Lewis, J. (2010). Evaluation of spasticity in children with cerebral palsy using Ashworth and Tardieu Scales compared with laboratory measures. Journal of Child Neurology, 25(10), 1242-1247. doi:10.1177/0883073810362266

Ansari, N. N., Naghdi, S., Hasson, S., Rastgoo, M., Amini, M., \& Forogh, B. (2013). Clinical assessment of ankle plantarflexor spasticity in adult patients after stroke: Inter-and intra-rater reliability of the Modified Tardieu Scale. Brain Injury, 27(5), 605-612. doi: 10.3109/02699052.2012.750744

Bar-On, L., Van Campenhout, A., Desloovere, K., Aertbelien, E., Huenaerts, C., Vandendoorent, B., ... Molnaers, G. (2014). Is an instrumented spasticity assessment an improvement over Clinical Spasticity Scales in Assessing and predicting the response to integrated Botulinum Toxin Type A treatment in children with cerebral palsy? Archives of Physical Medicine and Rehabilitation, 95, 515-523. doi: 10.1016/j. apmr.2013.08.010

Bartholomeusz, H. H., Courchesne, E., \& Karns, C. M. (2002). Relationship between head circumference and brain volume in healthy normal toddlers, children, and adults. Neuropediatrics, 33, 239-241. doi: 10.1055/s2002-36735

Bizzini, M., \& Mannion, A. F. (2003). Reliability of a new, hand-held device for assessing skeletal muscle stiffness. Clinical Biomechanics, 18, 459-461. doi: 10.1016/ S0268-0033(03)00042-1

Domholdt, K. (1993). Physical therapy research: Principles and applications. Philadelphia: WB Saunders Company.

Fleiss, J. (2007). Reliability of measurement. In J. Fleiss (Ed.), The design and analysis of clinical experiments (pp. 1-32). New York: John Wiley and Sons.

Fletcher, J., \& Bandy, W. (2008). Intratester reliability of CROM measurement of cervical spine active range of movement in persons with and without neck pain. Journal of Orthopaedic \& Sports Physical Therapy, 38, 640-643.

Gapeyeva, H., Mitt, P., Ereline, J., \& Pääsuke, M. (2015). Influence of 3-month physical therapy using the Atlant neuro-othopedic pneumosuit in preschool children with spastic cerebral palsy: Changes in muscle tone characteristics. Journal of Rehabilitation Medicine: Abstracts, The 9th World Congress of International Society of Physical and Rehabilitation Medicine, 54, 341-342.

Gapeyeva, H., \& Vain, A. (2007). Assessment of tone of superficial skeletal muscles in case of spastic hemiplegia: possibilities of myometry. In: Proceedings of the 4th Congress of the International Society of Physical and Rehabilitation Medicine (pp. 37-42). Bologna: Monduzzi Editore.

Gapeyeva, H., \& Vain, A. (2008). Myotoni kasutamine taastusravis. Müomeetria Ltd., Tartu.

Gavronski, G., Veraksitš, A., Vasar, E., \& Maaroos, J. (2007). Evaluation of viscoelastic parameters of the skeletal muscles in junior triathletes. Physiological Measurement, 28, 625-637.

Lidström, A., Ahlsten, G., Hirchfeld, H., \& Norrlin, S. (2009). Intrarater and interrater reliability of myotonometer measurements of muscle tone in children. Journal of Child Neurology, 24(3), 267-274.

Marusiak, J., Kisiel-Sajewicz, K., Jaskolska, A., \& Jaskolski, A. (2010). Higher muscle passive stiffness in Parkinson's disease patients than in controls measured by myotonometry. Archives of Physical Medicine and Rehabilitation, 91(5), 800-802.

Murayama, M., Watanabe, K., Kato, R., Uchiyama, T., \& Yoneda, T. (2012). Association of muscle hardness with muscle tension dynamics: a physiological property. European Journal of Applied Physiology, 112(1), 105112. doi: 10.1007/s00421-011-1959-3

Oliva-Pascual-Vaca, A., Marcos Heredia-Rizo, A. M., Barbosa-Romero, A., Oliva-Pascual-Vaca, J., RodríguezBlanco, C., \& Tejero-García, S. (2014). Assessment of paraspinal muscle hardness in subjects with a mild single scoliosis curve: A preliminary myotonometer study. Journal of Manipulative and Physiological Therapeutics, 37(5), 32-333. doi: 10.1016/j.jmpt.2014.03.001

Pomeroy, V. M., Dean, D., Sykes, L., Faragher, E. B., Yates, M., Tyrell, P. J., ... Tallis, R. C. (2000). The unreliability of clinical measures of muscle tone: Implications for stroke therapy. Age and Ageing, 29, 229-233. doi:10.1093/ageing/29.3.229

Shrout, P., \& Fleiss, J. (1979). Intraclass correlations: uses in assessing rater reliability. Psychological Bulletin, $86,420-428$.

Straubegaite, L., Bernecke, V., Muckus, K., \& Juodžbaliene, V. (2011). The effect of horse-back riding on passive mechanical properties of child's extensor spine muscles. Special Education, 2(25), 150-156. 
Straubergaite, L., Juodžbaliene, V., Tolocka, R. T., \& Muckus, K. (2012). The effect of physiotherapy on the symmetry of passive mechanical properties of muscles of children with and without cerebral palsy. Mechanika, 18(6), 721-725.

Vahimets, M., Gapeyeva, H., Ereline, J., Pääsuke, M., Kaasik, P., \& Vain, A. (2006). Influence of trigenics myoneural treatment on lower extremities muscle tone and viscous-elastic properties in young basketball players. Acta Academiae Olympiquae Estoniae, 14, 49-68.

Vain, A., Kums, T., Ereline, J., Pääsuke, M., \& Gapeyeva, H. (2015). Gastrocnemius muscle tone, elasticity, and stiffness in association with postural control characteristics in young men. Proceedings of the Estonian Academy of Sciences, 64(4), 525-534.
Vain, A. (2002). Role of skeletal muscle tone and elasticity in the workability restoration of male crosscountry skiers. Acta Academiae Olympique Estoniae, 10, 95-108.

Viir, R., Laiho, K., Kramarenko, J., \& Mikkelson, M. (2006). Repeatability of trapezius muscle tone assessment by myometric method. Journal of Mechanics in Medicine and Biology, 6(2), 215-228.

Yam, W. K. L., \& Leung, M. S. M. (2006). Interrater reliability of Modified Ashworth Scale and Modified Tardieu Scale in children with spastic cerebral palsy. Journal of Child Neurology, 21, 1031-1035. doi: 10.1177/7010.2006.00222 